\title{
DUAL SOLUTIONS FOR BOUNDARY LAYER FLOW OF MOVING FLUID OVER A MOVING SURFACE WITH POWER-LAW SURFACE TEMPERATURE
}

\author{
S. MUKHOPADHYAY \\ Department of Mathematics, University of Burdwan \\ Burdwan-713104, W.B., INDIA \\ E-mail: swati_bumath@yahoo.co.in \\ R.S.R. GORLA* \\ Department of Mechanical Engineering \\ Cleveland State University \\ Cleveland, OH 44115, USA \\ E-mail: r.gorla@csuohio.edu
}

\begin{abstract}
An analysis of heat transfer for boundary layer forced convective flow past a moving flat surface parallel to a moving stream is presented. The power-law surface temperature at the boundary is prescribed. The surface temperature varying directly (or inversely) with power-law exponent is considered. The similarity solutions for the problem are obtained and the reduced ordinary differential equations are solved numerically. To support the validity of the numerical results, a comparison is made with known results from the open literature for some particular cases of the present study. When the surface and the fluid move in the opposite directions, dual solutions exist.
\end{abstract}

Key words: forced convective flow, moving fluid, flat surface, power-law surface temperature, dual solutions.

\section{Introduction}

From both theoretical and experimental standpoint, forced convection over a flat plate/sheet has been widely studied over the past few decades. Earlier investigators were mainly interested in finding the similarity solutions for the boundary layer flow problems. In fluid mechanics, the problem of a viscous boundary-layer flow on a moving or fixed flat plate is a classical problem. Flow and heat transfer of a viscous fluid over a moving surface has many important applications in modern industry, viz. polymer industry, glass fiber drawing, crystal growing, plastic extrusion, continuous casting, etc. (Magyari and Keller, 2000).

The boundary layer flow on a flat plate was investigated by different researchers, viz. Blasius (1908), Howarth (1938), Abussita (1994), Wang (2004) etc. For the boundary layer flow on a moving flat plate in a quiescent fluid, Sakiadis (1961) obtained the same equations as obtained by Blasius (1908) with different boundary conditions. By introducing composite velocity, Afzal et al. (1993) combined Blasius and Sakiadis problems successfully and obtained a single set of equations. Recently, the Blasius and Sakiadis problems were extended respectively by Batallar (2008) and Cortell (2008) by studying the effects of radiation on the boundary layer. Considering the suction/blowing effect on the boundary, a new dimension is added to the above mentioned study by Ishak (2009).

\footnotetext{
* To whom correspondence should be addressed
} 
Siekman (1962), Klemp and Acrivos (1976), Abdulhafez (1985), Chappidi and Gunnerson (1989), Hussaini et al. (1987), Lin and Haung (1994) and Sparrow and Abraham (2005) reported the flow, heat transfer characteristics for moving wall laminar boundary layer problems.

Cortell (2007) extended the work of Afzal et al. (1993) for constant as well as prescribed power-law surface temperature. However, the existence of dual solutions was not discussed in that study. Recently, Ishak et al. (2009) showed that dual solutions exist when the velocity ratio exceeds unity, i.e., the sheet moves in opposite direction to the free stream. The effects of suction and injection on the flow and thermal fields for constant surface temperature were also reported in that study. But in his study the prescribed surface temperature was disregarded. Of late, Mukhopadhyay (2011) investigated the case of prescribed surface temperature of the second degree and reported the existence of dual solutions. In this present investigation more general power-law surface temperature at the boundary is considered. The surface temperature is assumed to vary directly (or inversely) with the power-law exponent. For prescribed surface temperature, dual solutions also exist and these are presented and explained through their graphical representations.

\section{Formulation of the problem}

We consider a forced convective, two-dimensional steady laminar boundary-layer flow of an incompressible, viscous fluid over a flat surface moving with constant velocity $U_{w}$ in the same or opposite direction to the free stream $U_{\infty}$ (directed towards the positive x-direction). The $x$-axis extends parallel to the surface, while the $y$-axis extends upwards, normal to the surface.

The governing equations for boundary layer flows and heat transfer are written as

$$
\begin{aligned}
& \frac{\partial u}{\partial x}+\frac{\partial v}{\partial y}=0 \\
& u \frac{\partial u}{\partial x}+v \frac{\partial u}{\partial y}=v \frac{\partial^{2} u}{\partial y^{2}}, \\
& u \frac{\partial T}{\partial x}+v \frac{\partial T}{\partial y}=\frac{\kappa}{\rho c_{p}} \frac{\partial^{2} T}{\partial y^{2}}
\end{aligned}
$$

where $u$ and $v$ are the components of velocity respectively in the $x$ and $y$ directions, $\mu$ is the coefficient of fluid viscosity, $\rho$ is the fluid density, $v=\mu / \rho$ is the kinematic viscosity, $T$ is the temperature, $\kappa$ is the thermal conductivity of the fluid, $c_{p}$ is the specific heat at constant pressure.

Since the velocity of the fluid is low (laminar flow), the viscous dissipative heat is assumed to be negligible here.

The appropriate boundary conditions for the problem are given by

$$
\begin{aligned}
& u=U_{w}, \quad \mathrm{v}=0, \quad T=T_{w} \quad \text { at } \quad y=0, \\
& u \rightarrow U_{\infty}, \quad T \rightarrow T_{\infty} \quad \text { as } \quad y \rightarrow \infty .
\end{aligned}
$$

Here $T_{w}=T_{\infty}+A x^{n}$ is the prescribed surface temperature, $n$ is the power law exponent, $n>0$ presents the case when the surface temperature varies directly with $n$ whereas $n<0$ is the case when the surface temperature varies inversely with $n . T_{\infty}$ is the free stream temperature assumed constant. 


\subsection{Similarity analysis and solution procedure}

With the help of a composite velocity $U=U_{w}+U_{\infty}$, we now introduce the following dimensionless variables

$$
\begin{aligned}
& \eta=y \sqrt{\frac{U}{2 v x}}, \quad u=U f^{\prime}(\eta), \quad v=U \frac{\eta f^{\prime}(\eta)-f(\eta)}{\sqrt{2 \mathrm{Re}_{x}}}, \\
& \theta=\frac{T-T_{\infty}}{T_{w}-T_{\infty}}
\end{aligned}
$$

$\mathrm{Re}_{x}=\frac{U x}{v}$ is the local Reynolds number.

Using the relations (2.6) and (2.7) in the boundary layer Eq.(2.2) and in the energy Eq.(2.3) we get the following equations

$$
\begin{aligned}
& f^{\prime \prime \prime}+f f^{\prime \prime}=0 \\
& \theta^{\prime \prime}+\operatorname{Pr}\left(f \theta^{\prime}-2 n f^{\prime} \theta\right)=0
\end{aligned}
$$

where $\operatorname{Pr}=\frac{\mu c_{p}}{\kappa}$ is the Prandtl number.

The boundary conditions (2.4) and (2.5) then become

$$
f^{\prime}=1-r, \quad f=0, \quad \theta=1 \quad \text { at } \quad \eta=0,
$$

and

$$
f^{\prime}=r, \quad \theta=0 \quad \text { at } \quad \eta \rightarrow \infty
$$

where $r=\frac{U_{\infty}}{U}$ is the velocity ratio parameter.

Equations (2.8) and (2.9) along with boundary conditions were solved numerically by the shooting method (Mukhopadhyay et al., 2011; Bhattacharyya et al., 2011).

The details about the directions of the moving wall and the free stream can be found in Mukhopadhyay (2011).

\section{Results and discussions}

In order to get a clear insight to the physical problem, numerical computations have been carried out using the shooting method for various values of different parameters such as the velocity ratio parameter $(r)$, power-law exponent $(n)$ and Prandtl number (Pr) encountered in this problem. For illustrations of the results, numerical values are plotted in Fig.1a to Fig.6b.

In order to assess the accuracy of the method, the numerical results, obtained in this study, are compared with those of Ishak et al. (2009) for variable $r(r>1)$ and presented in Tab.1. The results are found to agree well. 
Table 1 . Values of velocity gradient $f^{/ /}(0)$ for non-porous flat surface.

\begin{tabular}{|c|c|c|c|c|}
\hline \multirow{3}{*}{$r$} & \multicolumn{4}{|c|}{$f^{\prime \prime}(0)$} \\
\hline & \multicolumn{2}{|c|}{ Ishak et al. (2009) } & \multicolumn{2}{|c|}{ Present study } \\
\hline & Upper branch & Lower branch & Upper branch & ower branch \\
\hline 1.1 & 0.533708 & 0.001493 & 0.533707 & 0.001491 \\
\hline 1.2 & 0.583178 & 0.016171 & 0.583176 & 0.016172 \\
\hline 1.3 & 0.613646 & 0.051941 & 0.613645 & 0.051940 \\
\hline 1.4 & 0.616140 & 0.117886 & 0.616142 & 0.117885 \\
\hline 1.5 & 0.565821 & 0.241872 & 0.565823 & 0.241874 \\
\hline
\end{tabular}

Figures $1 \mathrm{a}-1 \mathrm{~b}$ show the existence of two different temperature as well as temperature gradient profiles for variable values of the power-law exponent $n$ when the surface temperature varies directly with $n$, respectively. When the surface temperature varies inversely with the power-law exponent $n$, a temperature overshoot is noted (Fig.2a). Temperature increases with increasing absolute values of $n$ (for negative values of $n$ ). When $\mathrm{n}$ increases, the thermal boundary layer thickness decreases (Fig.2b). No temperature overshoot is noted for positive values of $n$ (Fig.1a).

Figures 3a-b illustrate the dual nature of temperature and temperature gradient profiles for variable values of the velocity ratio parameter $r$ for a fixed value of $n$ when the surface temperature varies directly with the power-law exponent $n$. For the upper branch solution, temperature is found to increase with increasing velocity ratio parameter $r$ but temperature decreases with $r$ for the lower branch solution (Fig.3a). In this case, the effect of $r$ on the temperature profiles for lower branch solutions is significant than that of upper branch solutions. Near the plate, the absolute value of temperature gradient increases with increasing $r$ but away from the plate an opposite behaviour is noted for the upper branch solution (Fig.3b). For the lower branch solution, the behaviour of temperature gradient is just opposite to that of the upper branch one. The wall temperature gradient is negative for all cases considered here which implies that heat is transferred from the plate surface to the fluid (Fig.3b). When the surface temperature varies inversely with $n$, temperature increases with $r$ (for the upper branch solution) but for the lower branch, though the temperature initially increases with $r$ but away from the plate, temperature decreases with $r$ (Fig.4a). A temperature overshoot is noted for both the upper branch and lower branch solution. For this case, the temperature gradient at the wall is positive for all values of $r$ considered, i.e., the heat is always transferred from the ambient fluid to the plate surface (Fig.4b).

The dual nature of temperature and temperature gradient for variable values of the Prandtl number for $n=0.5$ (when the surface temperature varies directly with $n$ ) is presented through Figs 5a-b respectively. Temperature decreases with increasing the Prandtl number for both the upper and lower branch solutions (Fig.5a). For the lower branch solutions, the boundary layer thickness is higher compared to that of the upper branch solutions. From this one can conclude that the upper branch solutions are stable while the lower branch solutions are not. An increase in the Prandtl number results in an increase in the heat transfer rate (Fig.5b). The fluid with a higher Prandtl number has a relatively low thermal conductivity and thereby reduces the thermal boundary layer thickness and as a result the heat transfer rate at the surface increases. 
a)

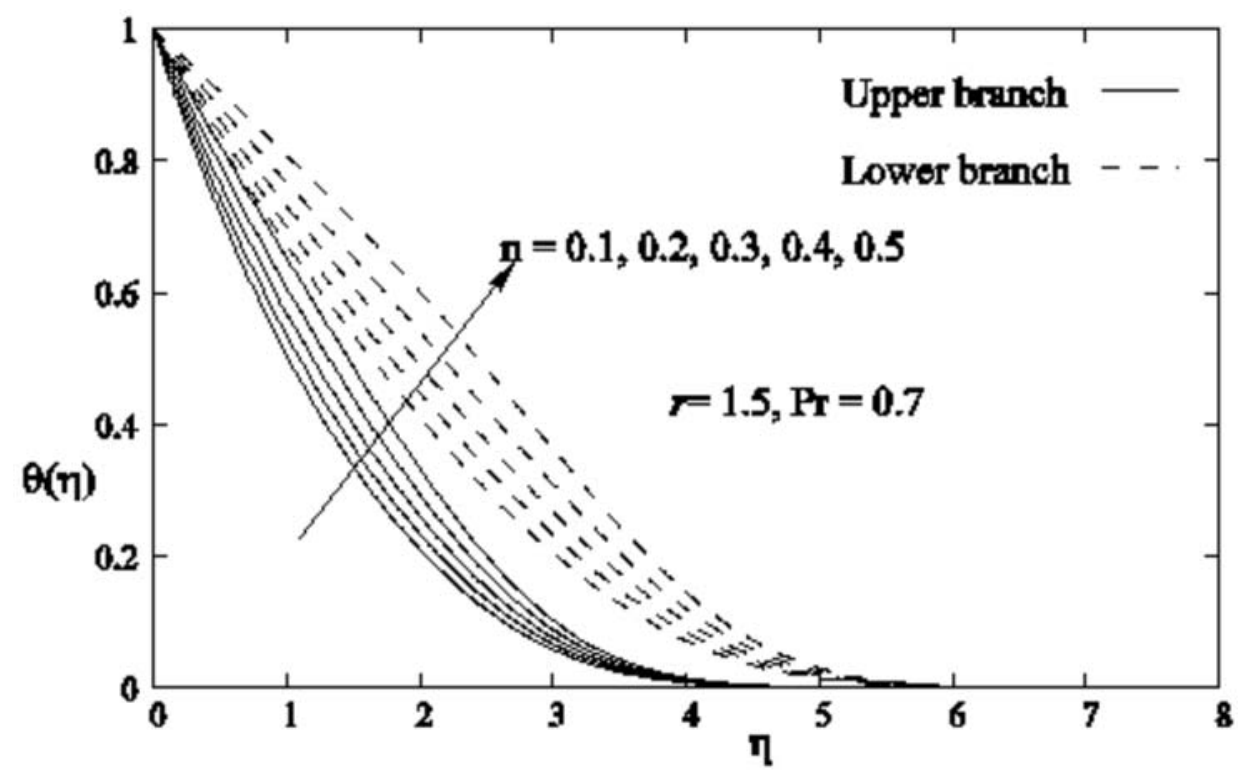

b)

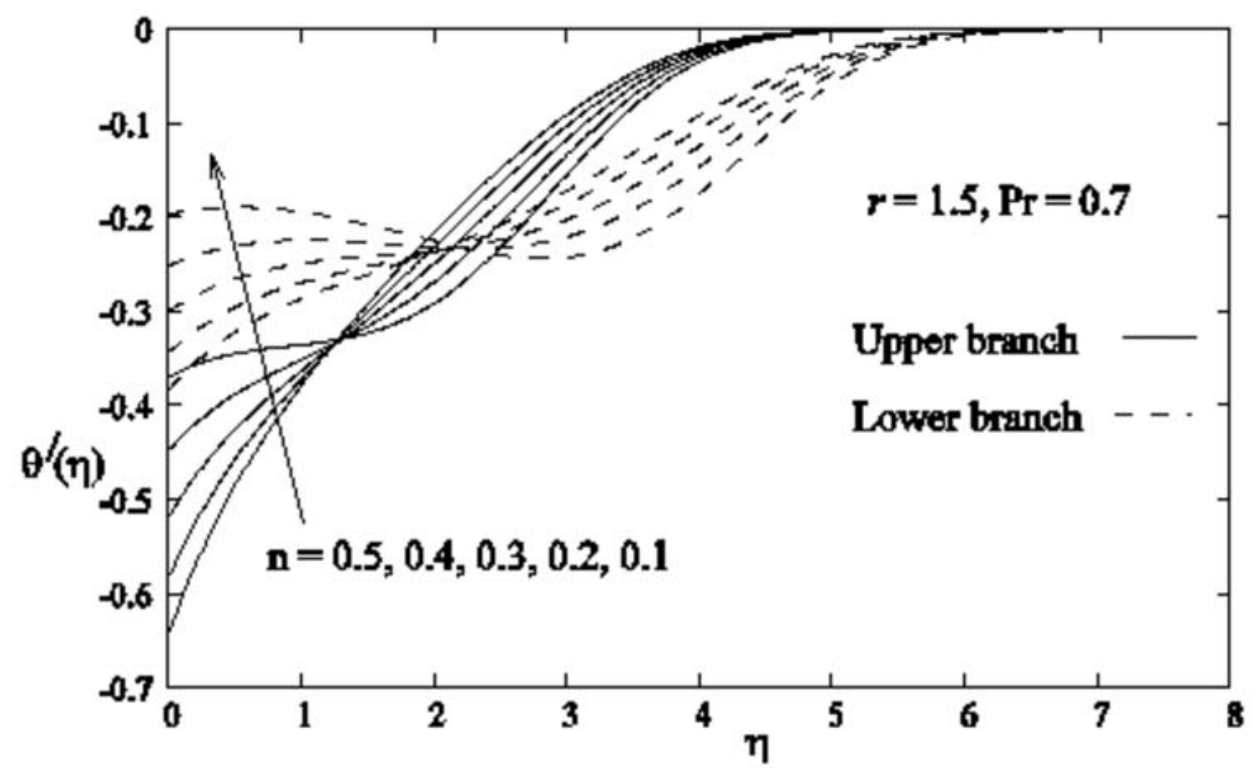

Fig.1. Dual nature of (a) temperature (b) temperature gradient profiles for several values of the power-law exponent $n$ when the surface temperature varies directly with the power-law exponent $n$. 
a)

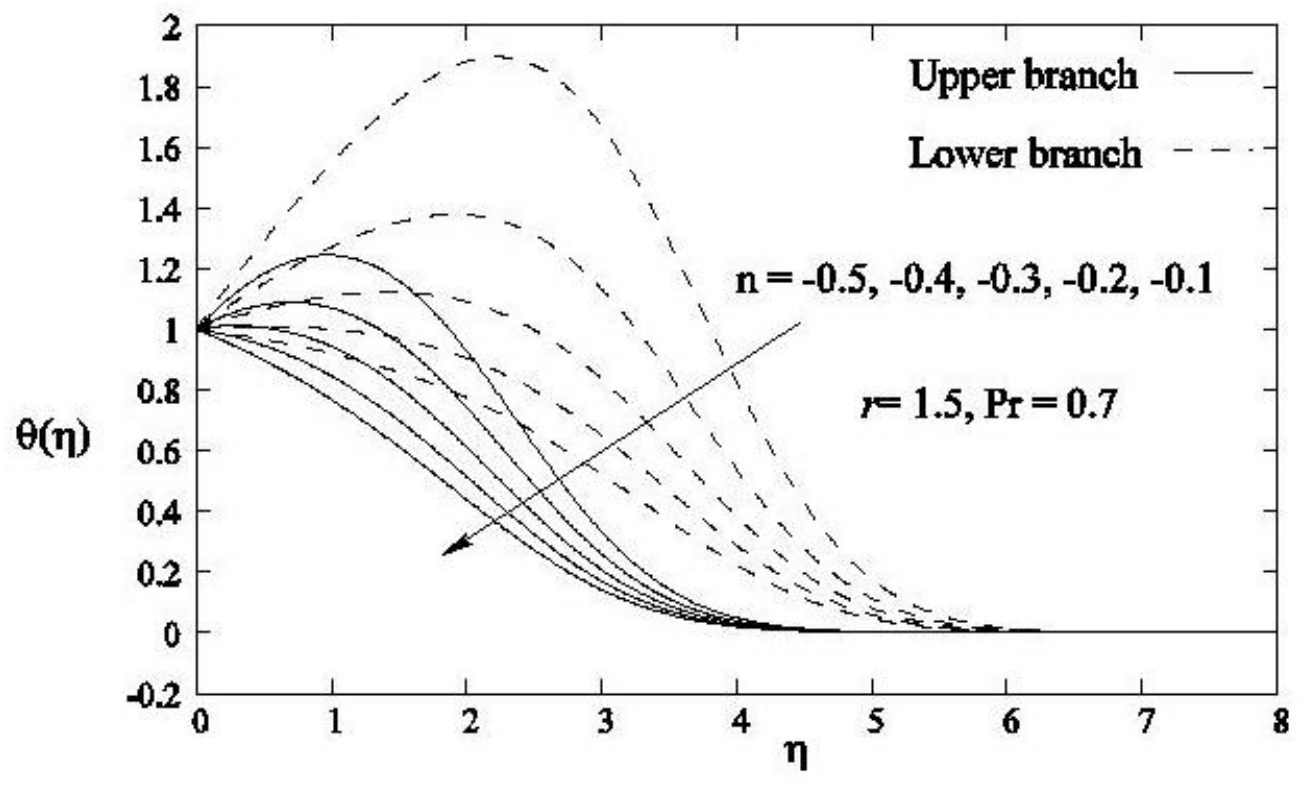

b)

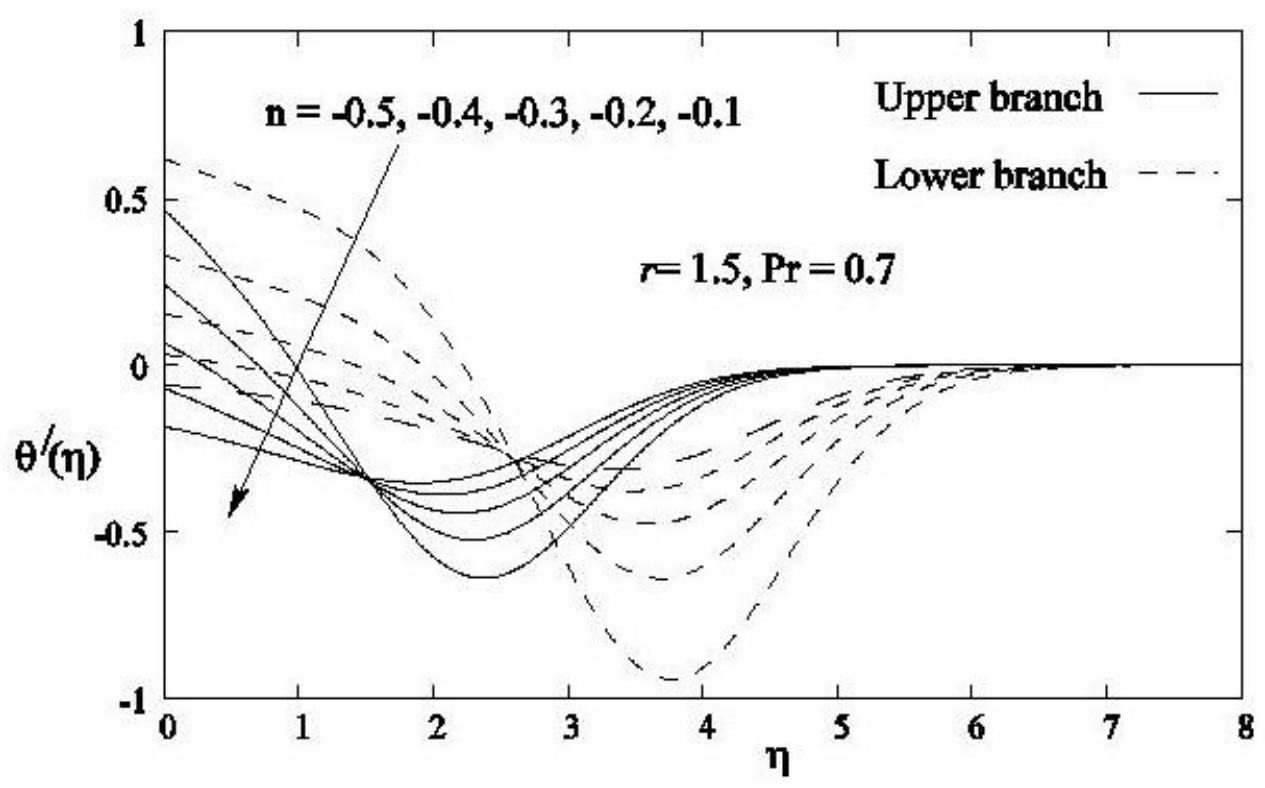

Fig.2. Dual nature of (a) temperature (b) temperature gradient profiles for several values of the power-law exponent $n$ when the surface temperature varies inversely with the power-law exponent $n$. 
a)

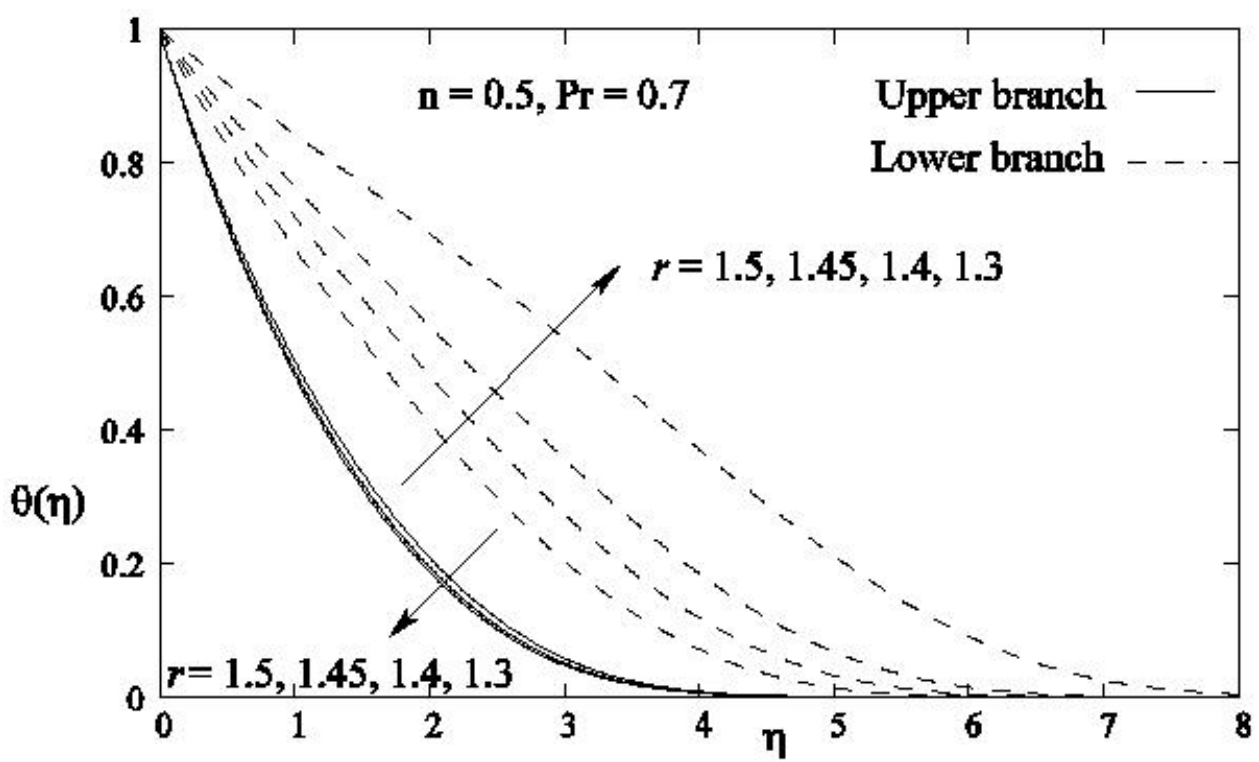

b)

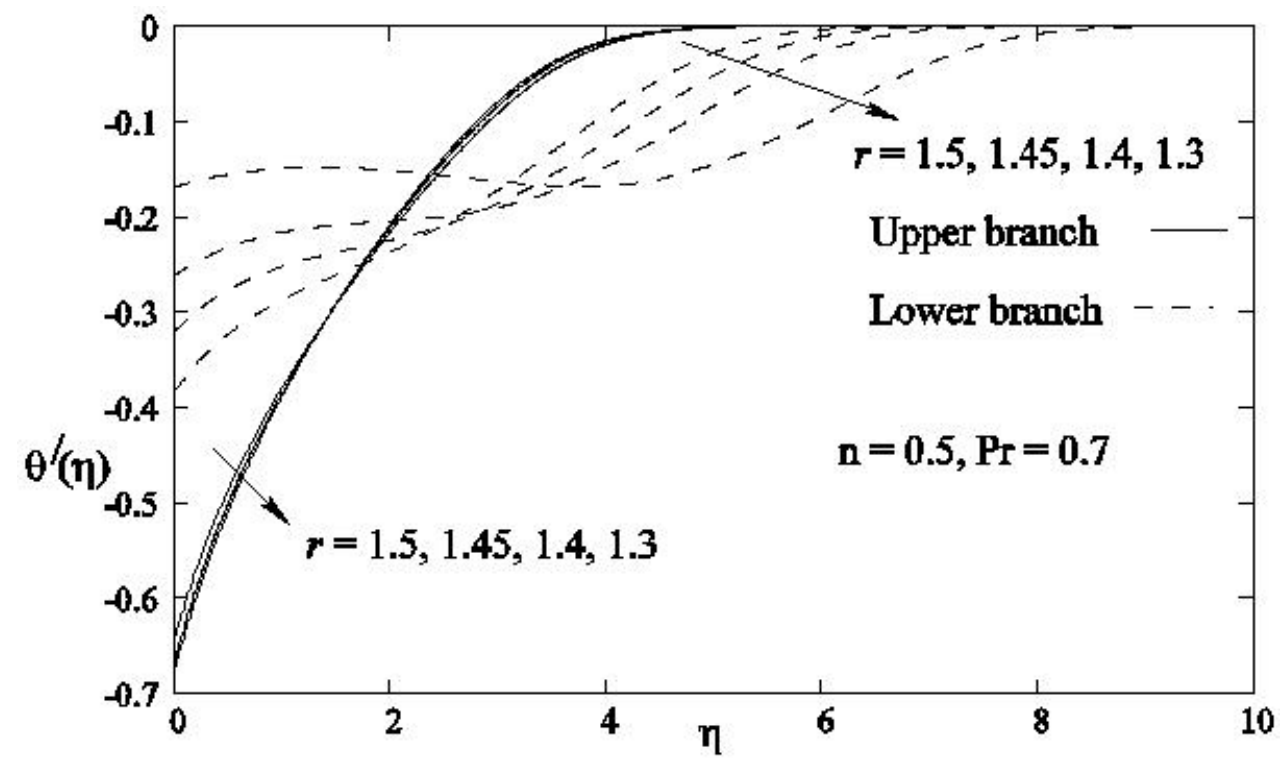

Fig.3. Dual nature of (a) temperature (b) temperature gradient profiles for several values of the velocity ratio parameter $r$ when the surface temperature varies directly with the power-law exponent $n$. 
a)

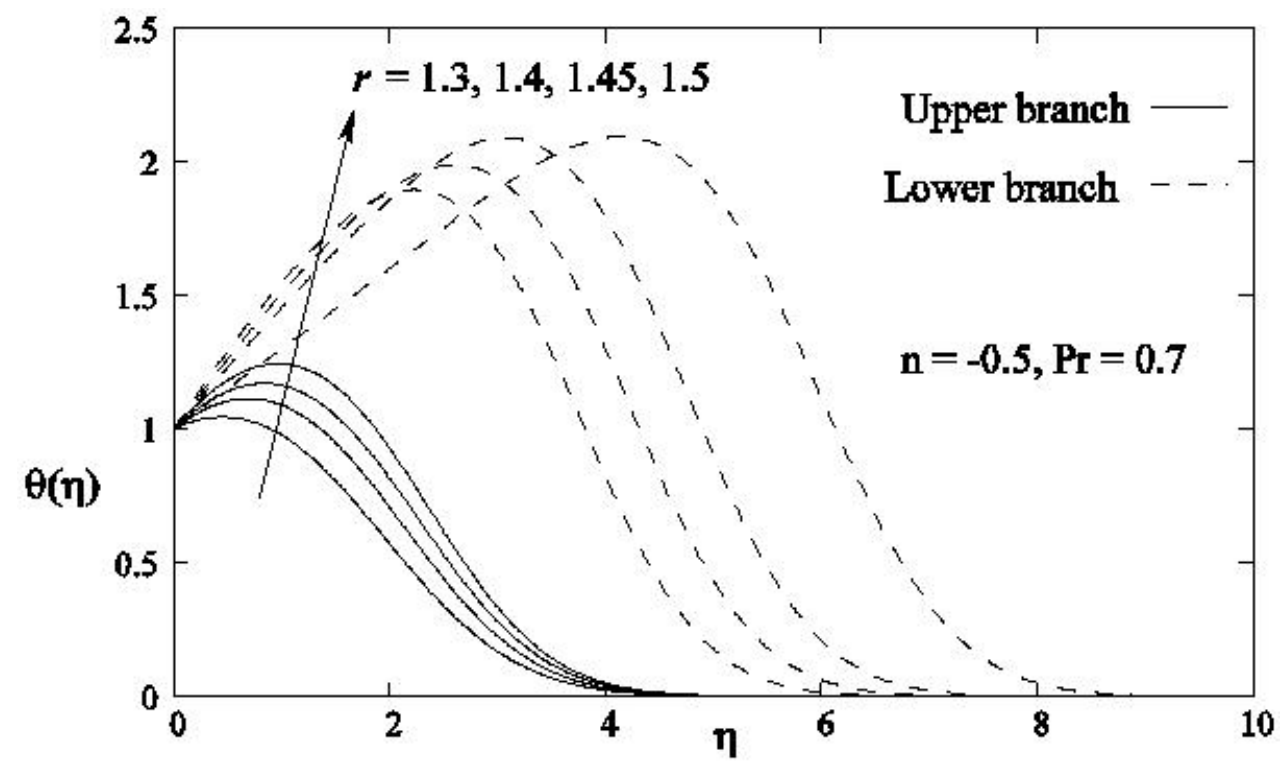

b)

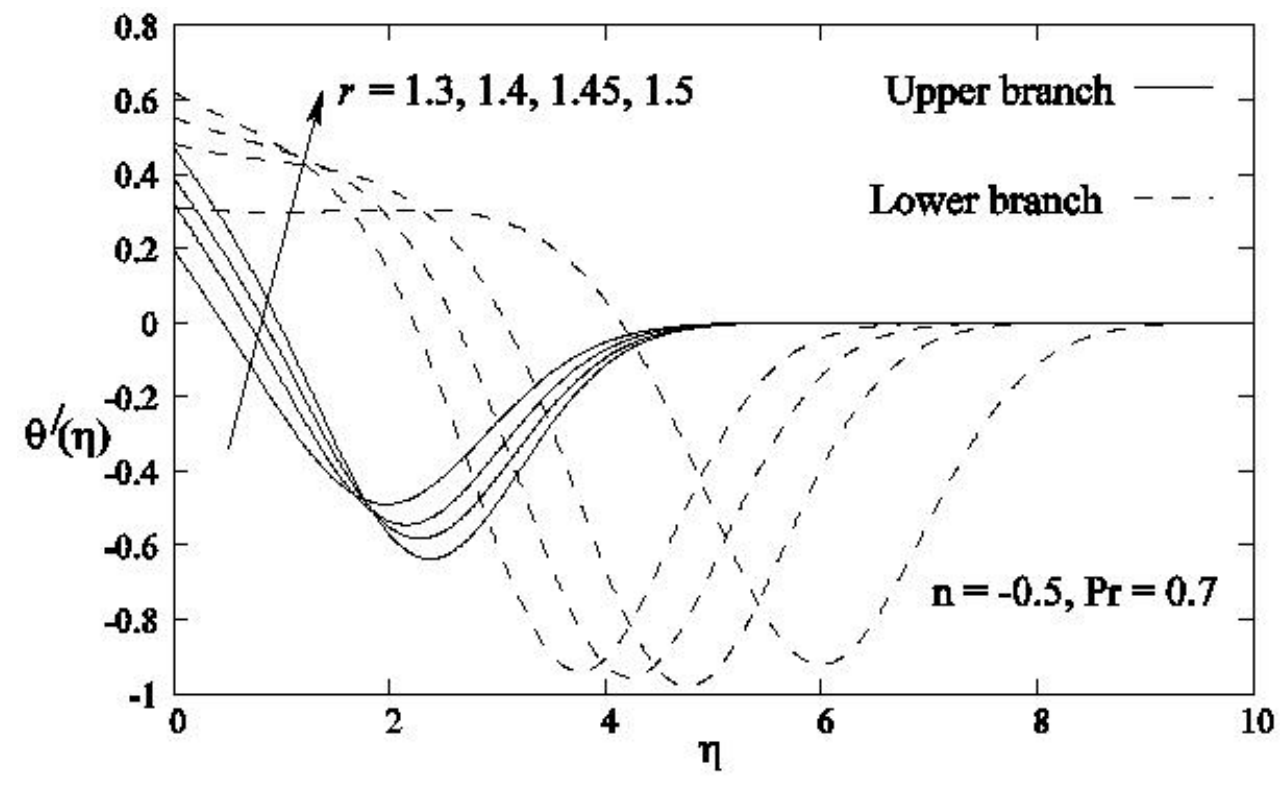

Fig.4. Dual nature of (a) temperature (b) temperature gradient profiles for several values of the velocity ratio parameter $r$ when the surface temperature varies inversely with the power-law exponent $n$. 
a)

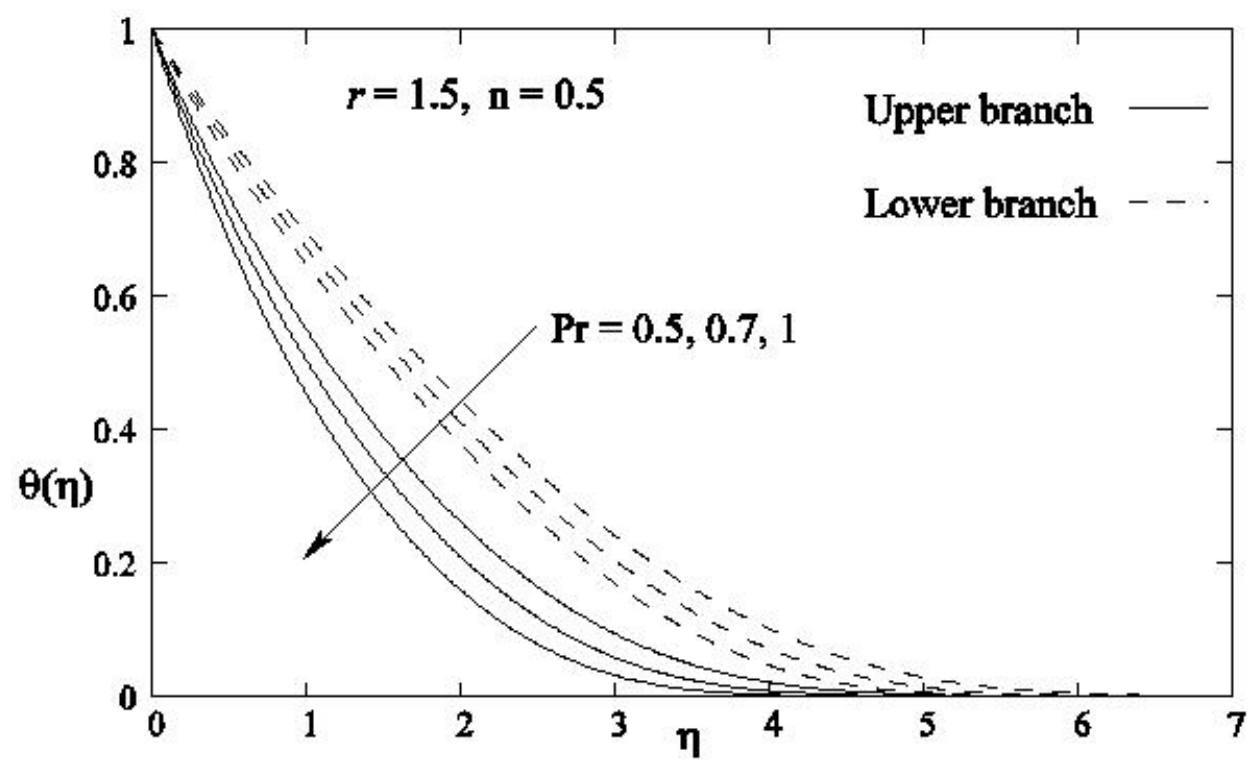

b)

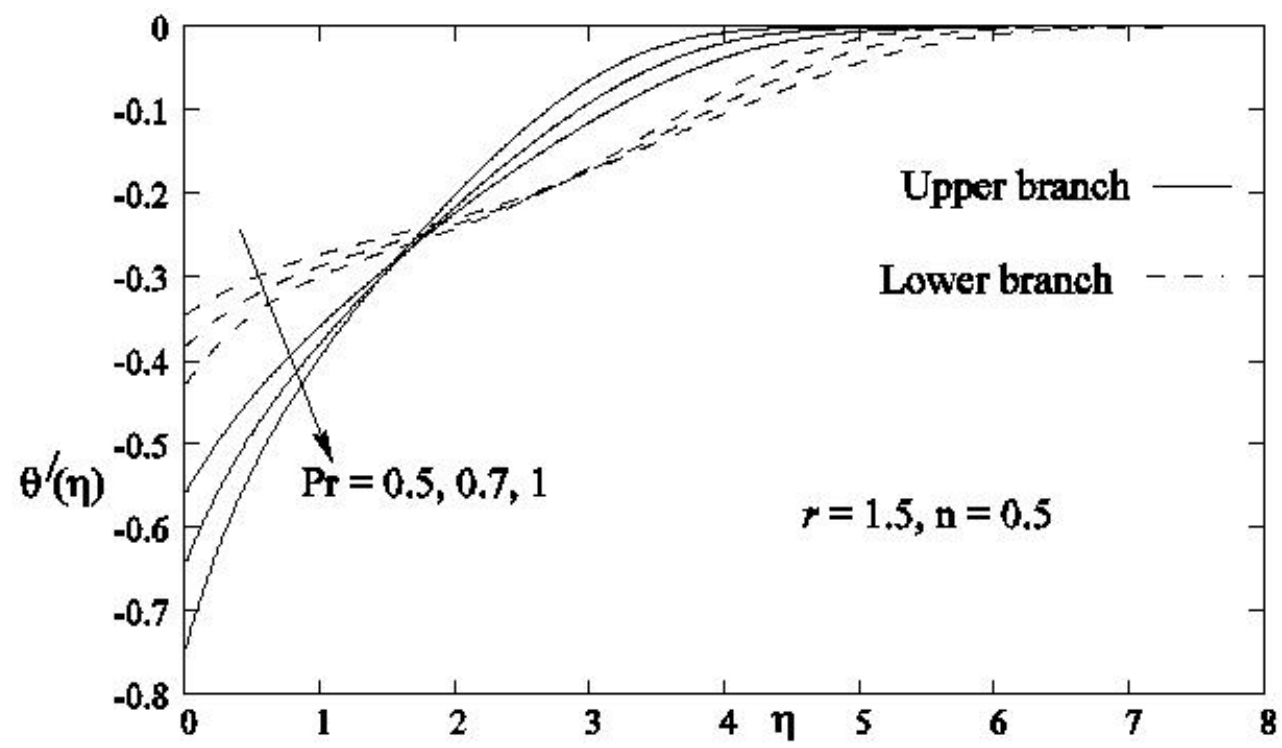

Fig.5. Dual nature of (a) temperature (b) temperature gradient profiles for several values of the Prandtl number Pr when the surface temperature varies directly with the power-law exponent $n$.

When the surface temperature varies inversely with $n$, initially the temperature is found to increase with increasing the Prandtl number for both the solutions but far away from the plate temperature gradually decreases with increasing the Prandtl number (Fig.6a). Here, the temperature gradient at the wall is positive for all $\operatorname{Pr}$ considered in this case (Fig.6b). 
a)

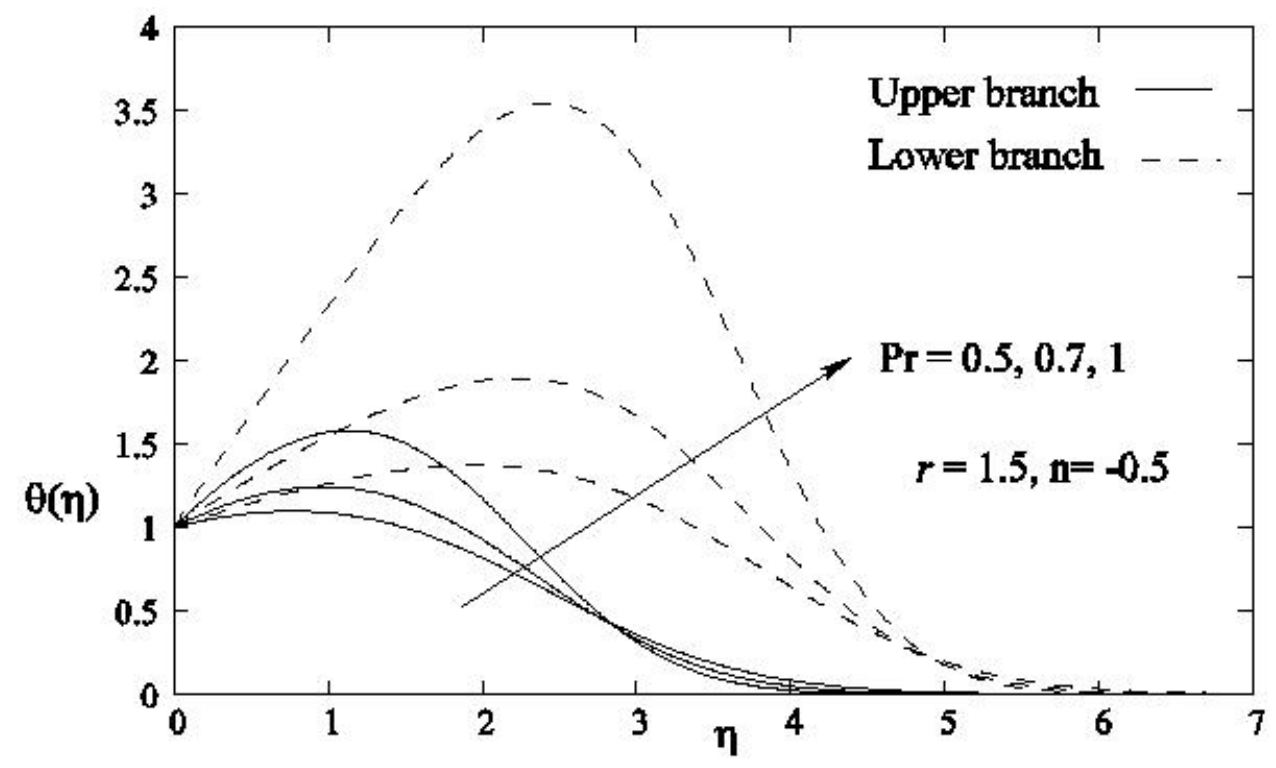

b)

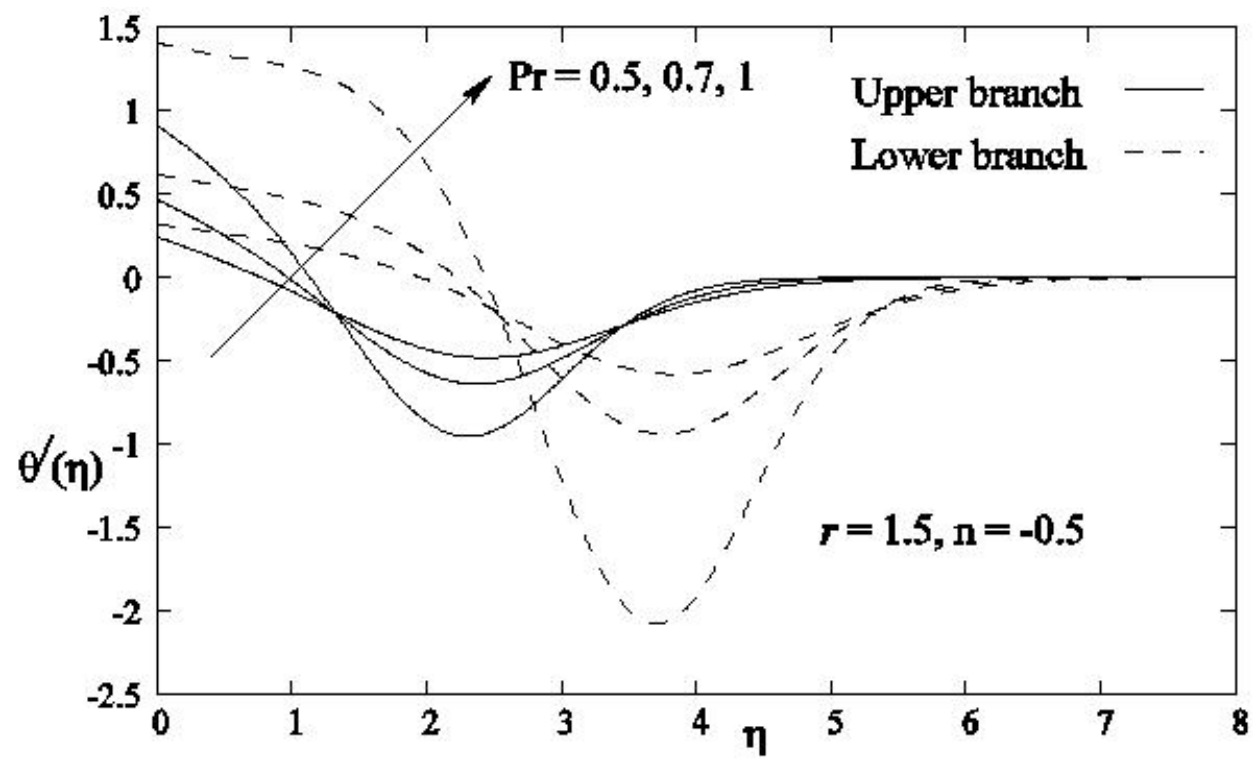

Fig.6. Dual nature of (a) temperature (b) temperature gradient profiles for several values of the Prandtl number Pr when the surface temperature varies inversely with the power-law exponent $n$.

\section{Conclusions}

Heat transfer characteristics for a moving non-isothermal surface parallel to a free stream with prescribed power-law surface temperature varying directly (or inversely) with the power-law exponent is 
presented. As usual, dual solutions are obtained when the plate and the fluid move in the opposite direction. A temperature overshoot is noted when the surface temperature varies inversely with the power-law index $n$.

\section{Nomenclature}

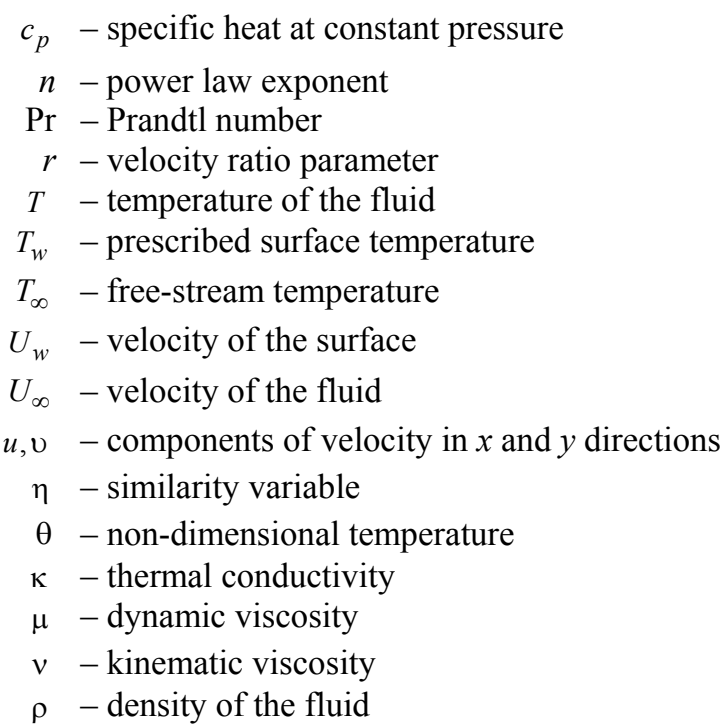

\section{References}

Abdulhafez T.A. (1985): Skin friction and heat transfer on a continuous flat surface moving in a parallel free stream.Int. J. Heat Mass Transf., vol.28, pp.1234-1237.

Abussita A.M.M. (1994): A note on a certain boundary-layer equation. - Appl. Math. Comp., vol.64, pp.73-77.

Afzal N., Badaruddin A. and Elgarvi A.A. (1993): Momentum and heat transport on a continuous flat surface moving in a parallel stream. - Int. J. of Heat Mass Transfer, vol.36, No.13, pp.3399-3403.

Bataller R.C. (2008): Radiation effects in the Blasius flow. - Appl. Math. Comp., vol.198, pp.333-338.

Bhattacharyya K., Mukhopadhyay S. and Layek G.C. (2011): Slip effects on boundary layer stagnation-point flow and heat transfer towards a shrinking sheet. - Int. J. of Heat and Mass Transfer, vol.54, pp.308-313.

Blasius H. (1908): Grenzschichten in Flüssigkeiten mit kleiner Reibung. - Zeitschrift für Mathematik und Physik, vol.56, pp.1-37.

Chappidi P.R. and Gunnerson F.S. (1989): Analysis of heat and momentum transport along a moving surface. - Int. J. Heat Mass Transf., vol.32, pp.1383-1386.

Cortell R. (2007): Flow and heat transfer in a moving fluid over a moving flat surface. - Theor. Comput. Fluid Dyn., vol.21, pp.435-446.

Cortell R. (2008): A numerical tackling on Sakiadis flow with thermal radiation. - Chin. Phys. Lett., vol.25, pp.13401342.

Howarth L. (1938): On the solution of the laminar boundary layer equations. - Proc. Roy. Soc. London A, vol.164, pp.547-579.

Hussaini M.Y., Lakin W.D. and Nachman A. (1987): On similarity solutions of a boundary-layer problem with an upstream moving wall. - SIAM J. Appl. Math., vol.47, pp.699-709.

Ishak A. (2009): Radiation effects on the flow and heat transfer over a moving plate in a parallel stream. - Chin. Phys. Lett., vol.26, No.3, 034701-034704. 
Ishak A., Nazar R. and Pop I. (2009): The effects of transpiration on the flow and heat transfer over a moving permeable surface in a parallel stream. - Chem. Engng. J., vol.148, pp.63-67.

Klemp J.B. and Acrivos A. (1976): The moving-wall boundary layer with reverse flow. - J. Fluid Mech., vol.76, pp.363-381.

Lin H.T. and Haung S.F. (1994): Flow and heat transfer of plane surface moving in parallel and reversely to the free stream. - Int. J. Heat Mass Transf., vol.37, pp.333-336.

Magyari E. and Keller B. (2000): Exact solutions for self-similar boundary-layer flows induced by permeable stretching walls. - Eur. J. Mech. B Fluids, vol.19, pp.109-122.

Mukhopadhyay S. (2011): Heat transfer in a moving fluid over a moving non-isothermal flat surface. - Chin. Phys. Lett., vol.28, No.12, 124706.

Mukhopadhyay S., Bhattacharyya K. and Layek G.C. (2011): Steady boundary layer flow and heat transfer over a porous moving plate in presence of thermal radiation. - Int. J. of Heat and Mass Transfer, vol.54, pp.2751-2757.

Sakiadis B.C. (1961): Boundary-layer behaviour on continuous solid surfaces: Boundary-layer equations for two dimensional and axisymmetric flow. - AIChE J., vol.7, pp.26-28.

Siekman J. (1962): The laminar boundary layer along a flat plate. - Z. Flugwiss., vol.10, pp.278-281.

Sparrow E.M. and Abraham J.P. (2005): Universal solutions for the streamwise variation of the temperature of a moving sheet in the presence of a moving fluid. - Int. J. Heat Mass Transf., vol.48, pp.3047-3056.

Wang L. (2004): A new algorithm for solving classical Blasius equation. - Appl. Math. Comp., vol.157, pp.1-9.

Received: February 27, 2012

Revised: July 2, 2012 